\title{
Discrimination and Stress Among Asian Refugee Populations During the COVID-19 Pandemic: Evidence from Bhutanese and Burmese Refugees in the USA
}

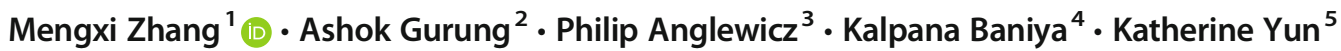

Received: 22 October 2020 / Revised: 4 February 2021 / Accepted: 7 February 2021 / Published online: 2 March 2021

(C) W. Montague Cobb-NMA Health Institute 2021

\begin{abstract}
Objectives To measure COVID-19 pandemic-related discrimination and stress among Bhutanese and Burmese refugees in the USA and to identify characteristics associated with these two measures.

Methods From 5/15-6/1/2020, Bhutanese and Burmese refugee community leaders were invited to complete an anonymous, online survey and shared the link with other community members who were English-proficient, $\geq 18$ years old, and currently living in the USA. We identified characteristics associated with pandemic-related discrimination and stress applying ordinal logistic regression models.

Results Among 218 refugees from 23 states, nearly one third of participants reported experiencing at least one type of discrimination, and more than two-thirds experienced at least one type of pandemic-related stress. Having had COVID-19, having a family member with COVID-19, and being an essential worker were associated with discrimination. Discrimination, financial crisis, and female gender were associated with stress.

Conclusions Reducing pandemic-related discrimination should remain a priority, as should the promotion of social support and coping strategies. Noting that this is a nonrepresentative sample, we recommend that larger national studies tracking experiences with pandemic-related discrimination and stress include Asian American subgroups with limited English proficiency.
\end{abstract}

Keywords COVID-19 pandemic $\cdot$ Bhutanese and Burmese refugees $\cdot$ Asian Americans $\cdot$ Racism $\cdot$ Discrimination $\cdot$ Mental health

\section{Introduction}

During the COVID-19 pandemic caused by novel coronavirus SARS-CoV-2, fear, rumors, and misconceptions about the novel coronavirus have placed Asian Americans in the spotlight of blame and harassment [1-5]. Instead of preventing discrimination and xenophobia, government officials repeatedly labeled the virus the "Wuhan coronavirus" or the "China virus," potentially accelerating COVID-19 related racial attacks on Asian Americans. In March 2020, the Federal Bureau of Investigation issued a warning about a potential surge of hate crimes against Asian Americans [6]. In April 2020, the Center for Public Integrity reported that $32 \%$ of Americans have witnessed someone blaming Asian people for the pandemic [7]. From March 19 through August 5, 2020 , over 2,500 instances of anti-Asian discrimination
Mengxi Zhang

mzhang2@bsu.edu

Ashok Gurung

gurunga@email.chop.edu

Philip Anglewicz

panglew1@jhu.edu

Kalpana Baniya

baniyakalpana21@gmail.com

Katherine Yun

YunK@email.chop.edu
1 Department of Nutrition and Health Science, Ball State University College of Health, Muncie, IN, USA

2 PolicyLab, Children's Hospital of Philadelphia, Philadelphia, PA, USA

3 Department of Population, Family and Reproductive Health, Johns Hopkins Bloomberg School of Public Health, Baltimore, MD, USA

4 School of Nursing, Middle Tennessee State University, Murfreesboro, TN, USA

5 Division of General Pediatrics, Children's Hospital of Philadelphia \& University of Pennsylvania Perelman School of Medicine Philadelphia, Philadelphia, PA, USA 
were reported to the Stop AAPI Hate Tracker, an online tool for reporting incidents of hate, violence, or discrimination against Asian Americans and Pacific Islanders in the USA [8]. Such discrimination may contribute to long-term distress, including depression, trauma, anxiety, and posttraumatic stress disorder $[3,9,10]$. The experience and magnitude of race-based traumatic stress can further impact individuals' perceptions of their ability to cope with such events [11].

Coping with anti-Asian discrimination and stress may be particularly challenging for Asian-origin refugees. Refugees with limited English proficiency face difficulty reporting harassment or seeking assistance in their preferred languages [12]. Refugees with lower socioeconomic status have reduced access to support services and coping resources both due to cost and also due to competing demands, such as work schedules. Refugees from Asia are less likely to seek mental health services due to stigma regarding mental illness, concern about being perceived as "crazy" and decreased emphasis on psychological solutions for emotional stress [3, 13, 14]. These barriers may be further amplified among refugees who are fearful about speaking out and drawing attention to their experiences due to premigration political repression, including repression that targeted individuals who advocated for themselves and their communities [15]. Additionally, refugee communities often have large populations of essential workers who are unable to work from home, so they may be exposed to harassment at worksites or when traveling to and from work $[16,17]$. Further, refugees with a perceived risk of COVID-19 exposure through work, e.g., health care personnel, may experience discrimination and stigmatization by individuals fearful of infection $[18,19]$.

Despite these commonalities, experiences with pandemic-related discrimination are also believed to vary across different Asian American subgroups. The US Asian population comes from more than 20 countries, each with a unique history, language, and cultural background. Socialeconomic and health status look widely different across different Asian American subgroups, e.g., when comparing the experiences of English-proficient, white-collar professionals who migrate to the USA with the sponsorship of an employer versus those of predominantly working-class refugee communities. Though these differences significantly impact the risk of COVID-19 infection, very few states have included COVID-19 statistics for disaggregated Asian American subgroups in their public health reports. The majority of current research also ignores the heterogeneity of COVID-19 across different Asian American communities.

The Bhutanese and Burmese refugee communities are two Asian American subpopulations with multiple risk factors for COVID-19 related discrimination. Bhutanese and Burmese refugee communities are also among the largest refugee communities resettled in the USA between 2000 to 2015, and they have among the highest foreign-born shares of any Asian-origin communities in the USA (Bhutanese 92\%, Burmese $85 \%$ ) [20]. Both communities have relatively high poverty rates (Bhutanese 33\%; Burmese $35 \%$; Asian American 12\%; US population 15\%). They also have lower rates of English proficiency (Bhutanese 27\%; Burmese 28\%; Asian American 70\%) and are less likely to have a bachelor's degree relative to the general US population (Bhutanese 9\%; Burmese 24\%; Asian American 51\%; US population 30\%) $[20,21]$. The majority of Bhutanese refugees living in the USA are Nepali-speaking Lhotshampa who were forced to flee Bhutan due to political repression and ethnic violence culminating with the mass expulsion of Lhotshampa Bhutanese in the 1990s. After nearly two decades living in refugee camps in Nepal, this predominantly agrarian and multigenerational community was allowed to resettle in the USA beginning in 2007 [21]. Similarly, most Burmese migrants to the USA since 2006 are political refugees. Many come from rural regions where minority ethnic groups, such as the Karen and Chin, experienced recurrent repression and violence during armed conflicts between the national Burmese Army and ethnic opposition groups. More than a million people from Burma (now called Myanmar) have been displaced to neighboring countries, including Bangladesh, India, Malaysia, and Thailand. Most Burmese refugees in the USA lived in these areas prior to resettlement $[20,21]$.

For these reasons, we hypothesize that Bhutanese and Burmese refugees are at high risk of pandemic-related discrimination and stress. However, to date, there has been limited data describing the experiences of these refugee populations during the pandemic. In this study, we measure the distribution of pandemic-related discrimination and stress, as well as identify predictors of these two measures among Bhutanese and Burmese refugees in the USA.

\section{Material and Methods}

\section{Data Collection}

We conducted a cross-sectional study using a snowball sample. We limited participants to English-proficient individuals, age $\geq 18$ years, and currently living in the USA from 5/15/20 through $6 / 1 / 20$, we emailed or messaged an anonymous, online survey link to 19 bilingual Bhutanese and Burmese refugee community leaders identified through the study team's existing professional networks. These individuals were predominantly prior participants in community health leadership trainings or leaders of refugee-led community organizations. They were asked to complete the survey and share the link with peers who met inclusion criteria. To decrease potential selection bias, the survey invitation asked participants to share 
their experiences during the pandemic and did not specifically invite participants who had experienced discrimination. This study was approved by Ball State University's Human Research Protection Office (IRB\#: 1605425).

\section{Measures}

\section{Outcome}

To assess pandemic-related discrimination, participants were asked to answer three questions adapted from the Understanding America Study ${ }^{1}$, which asked if they had experienced the following at any time during the COVID-19 pandemic: (1) felt threatened or harassed from others as they think you might have the coronavirus, (2) felt others were afraid of you because they think might have the coronavirus, and (3) been treated with less respect than others because people think you might have the coronavirus. Responses were coded as binary variables with 1 (Yes) or 0 (No). We then generated an ordinal variable to measure the number of types of discrimination experienced by adding the outcomes of these three measures of discrimination. The ordinal discrimination measure was used for bivariate and multivariate analyses.

We measured pandemic-related stress by asking participants to rate the following stress experiences during the COVID-19 pandemic: (1) nervous about current circumstances, (2) worried about my health, (3) worried about my family's health, and (4) stressed about leaving the house. Response options ranged from $1=$ "does not apply at all" to $5=$ "strongly apply." We first coded these experiences as binary variables with 1 (strongly apply) or 0 (does not apply at all, somewhat does not apply, neither applies nor does not apply, or somewhat applies). We then generated an ordinal variable to measure the amount of stress experienced by summing these newly coded binary measures of stress. The ordinal stress measure was used for bivariate and multivariate analyses.

\section{Covariates}

Covariates included in the adjusted models for pandemicrelated discrimination were having had COVID-19, having a family member who had COVID-19, being an essential worker during the pandemic, gender, age, education, and years spent in the USA, as these covariates are known to be associated with discrimination and stress from previous studies [2, 23-26]. COVID-19 infection was measured as a binary, self-reported

\footnotetext{
${ }^{1}$ The Understanding America Study is a representative panel of households of approximately 9,000 respondents residing in the USA conducted by the University of Southern California [22].
}

outcome, using Yes/No responses to the following question, "Are you or have you been infected with the novel coronavirus?" Having a family member with COVID-19 was measured as a binary variable of whether anyone in the household is or has been infected with the novel coronavirus. Individuals working for pay at a job or business in the 7 days prior to survey completion were categorized as essential workers if their occupation corresponded to one described as providing "COVID-19 Essential Services" under Massachusetts Governor Baker's March 23, 2020 Emergency Order, updated on March 31 and April 28 [27]. Those whose occupation corresponded to essential services but who did not work in the past 7 days due to COVID-19 infection were also categorized as essential workers. Age was categorized as less than 31, between 31 and 40, and more than 40 considering the age distribution of our participants. Education was measured as secondary degree (junior high or senior high school), associate degree (community college, junior college, or technical school), and bachelor degree. Year spent in the USA was a continuous variable and represents an approximate measure of acculturation.

The model for pandemic-related stress included these covariates, pandemic-related financial crisis, and the ordinal measure for pandemic-related discrimination. Financial crisis was included because it is a common cause of emotional distress. Financial crisis was a binary variable capturing if the participants' family had experienced financial crisis during the coronavirus pandemic. Since the relationship between discrimination and stress has been established in other contexts, pandemic-related discrimination was also included here [28, 29].

\section{Statistical Model}

We first examined the distribution of each outcome and covariate. We then conducted bivariate analysis to measure the association between participants' characteristics and pandemic-related discrimination and stress. We applied Fisher's exact tests and one-way analysis of variance (ANOVA) tests to measure differences in pandemicrelated discrimination and stress across categorical variables and continuous variables, respectively. Finally, we identified characteristics associated with pandemic-related discrimination and stress, applying adjusted ordinal logistic regression models. We tested proportional odds assumption of ordered logistic regression models to measure if the coefficients are equal across categories. Multicollinearity was tested and not found. Less than 5\% of all measures were missing. Due to the small percentage, we considered all missing values to be missing at random. The significance level was set at 0.05 with a two-sided tail. Analysis was conducted using Stata/SE15.1. 
Table 1. Characteristics of Bhutanese and Burmese refugee participants in the USA in 2020

\begin{tabular}{|c|c|}
\hline & $\begin{array}{l}N=218 \\
\text { No. }(\%)\end{array}$ \\
\hline \multicolumn{2}{|l|}{ Ethnicity } \\
\hline Burmese & $30(13.76)$ \\
\hline Bhutanese & $188(86.24)$ \\
\hline \multicolumn{2}{|l|}{ Age } \\
\hline$\leq 30$ & $106(48.62)$ \\
\hline $31-40$ & $60(27.52)$ \\
\hline$\geq 41$ & $52(23.85)$ \\
\hline \multicolumn{2}{|l|}{ Gender } \\
\hline Male & $131(60.09)$ \\
\hline Female & $87(39.91)$ \\
\hline \multicolumn{2}{|l|}{ Education } \\
\hline Secondary degree & $58(26.61)$ \\
\hline Associate degree & $50(22.94)$ \\
\hline Bachelor or higher & $109(50.00)$ \\
\hline \multicolumn{2}{|l|}{ Household income } \\
\hline$\$ 0$ to $\$ 25,000$ & $35(16.06)$ \\
\hline$\$ 25,001$ to $\$ 50,000$ & $79(36.24)$ \\
\hline$\$ 50,001$ to $\$ 75,000$ & $57(26.15)$ \\
\hline$>\$ 75,000$ & $47(21.56)$ \\
\hline Years spent in the USA, mean (SD) & $9.99(3.01)$ \\
\hline \multicolumn{2}{|l|}{ Essential worker } \\
\hline Yes & $91(41.74)$ \\
\hline \multicolumn{2}{|l|}{ COVID-19 infection } \\
\hline Yes & $15(6.88)$ \\
\hline \multicolumn{2}{|l|}{ Having a family member infected } \\
\hline Yes & $15(6.88)$ \\
\hline \multicolumn{2}{|l|}{ Financial crisis } \\
\hline Yes & $80(36.70)$ \\
\hline
\end{tabular}

\section{Results}

Table 1 shows the characteristics of the study participants. In total, 218 Bhutanese and Burmese refugees from 23 states $^{2}$ completed the survey. The majority were Bhutanese (86.2\%), and just over half were male $(60.1 \%)$. Approximately half were more than 30 years old (52.4\%), received a bachelor's degree or higher $(50.0 \%)$, and had an annual household income less than $\$ 50,000(52.3 \%)$. The average time participants spent in the USA was 9.99 years. Nearly half of the participants were essential workers $(41.7 \%)$. Nonetheless, pandemic-related job loss (46.3\%) and family financial crisis

${ }^{2}$ California, Colorado, Georgia, Indiana, Iowa, Kentucky, Maryland, Massachusetts, Michigan, Minnesota, Missouri, Nebraska, New Hampshire, New York, North Carolina, North Dakota, Ohio, Pennsylvania, Tennessee, Texas, Vermont, Virginia, Washington. It covers the states which have the most Bhutanese and Burmese refugees in the USA [].
(36.7\%) were common. Nearly $7 \%$ of participants reported having been infected with the coronavirus. The same amount of the participants reported having family members infected with the coronavirus.

Table 2 displays experiences with pandemic-related discrimination. Nearly one third of the participants $(31.3 \%)$ reported experiencing at least one type of pandemic-related discrimination. A total of $15.1,9.6$, and $5.5 \%$ of the participants reported experiencing one, two, or three types of discrimination, respectively. Most often, participants reported feeling that other people were afraid of them (27.5\%). Additionally, $12.8 \%$ of respondents reported feeling threatened or harassed, and $10.6 \%$ reported feeling as if they had "been treated with less respect than others as people think you might have the novel coronavirus."

Table 2 also displays pandemic-related stress. More than two-thirds of participants (68.8\%) experienced at least one type of pandemic-related stress. A total of 25.2, 17.4, 12.4, and $13.8 \%$ of the participants reported experience one, two, three, or four types of stress, respectively. Specifically, nearly one third of participants strongly endorsed feeling nervous about the current circumstances (33.9\%), feeling worried about their health $(28.0 \%)$, or feeling stress about leaving home $(29.8 \%)$. Over half of participants strongly endorsed feeling worried about their family's health $(60.6 \%)$.

Table 2. COVID-9 related discrimination and stress among Bhutanese and Burmese refugee participants in the USA in 2020

\begin{tabular}{ll}
\hline & $N=218$ \\
& No. $(\%)$ \\
\hline Discrimination & \\
Threatened or harassed & $28(12.84)$ \\
Others acted as if afraid & $60(27.52)$ \\
Treated with less respect & $23(10.55)$ \\
Amount of discrimination experienced & \\
Zero & $152(69.72)$ \\
One & $33(15.14)$ \\
Two & $21(9.63)$ \\
Three & $12(5.50)$ \\
Stress & \\
Nervous about current circumstances & $74(33.94)$ \\
Worried about my health & $61(27.98)$ \\
Worried about my family's health & $132(60.55)$ \\
Stressed about leaving house & $65(29.82)$ \\
Amount of stress experienced & \\
Zero & $68(31.19)$ \\
One & $55(25.23)$ \\
Two & $38(17.43)$ \\
Three & $27(12.39)$ \\
Four & $30(13.76)$ \\
\hline
\end{tabular}


Table 3 displays the bivariate analysis of participants' characteristics and experiences with discrimination. Those who had COVID-19 $(P$ value $<0.001)$ and those family members had COVID-19 $(P$ value $<0.001)$ were more likely to experience more types of discrimination. The multivariate ordinal logistic regression model for pandemic-related discrimination is also shown in Table 3. History of COVID-19 (odds ratio [OR] 3.91; 95\% confidence interval [CI] 1.11, 13.86), having a family member with COVID-19 (OR 3.72; 95\% CI 1.08, 12.77), and being an essential worker (OR 2.03; 95\% CI 1.04, 3.97 ) increased participants' odds of experiencing more types of discrimination.
Table 4 shows the bivariate analysis of participants' characteristics and pandemic-related stress. Those who experienced more types of discrimination $(P$ value $<0.001)$, those who experienced financial crisis during the pandemic $(P$ value $=0.013)$, and women $(P$ value $=0.040)$ were more likely to experience more types of pandemic-related stress. Table 4 also displays the multivariate ordinal logistic regression model for pandemic-related stress. The results indicate a strong association between the amount of pandemic-related stress and the amount of pandemicrelated discrimination (one type of discrimination: OR 2.70, 95\% CI 1.31, 5.58; two types of discriminations:

Table 3. Predicators of COVID-19 pandemic-related discrimination among Bhutanese and Burmese refugee participants in the USA in 2020, applying bivariate analysis and adjusted ordinal logistic regression models ${ }^{\mathrm{a}}$

Amount of discrimination experienced ${ }^{\mathrm{b}}(N=218)$

\begin{tabular}{llllll}
\hline \multicolumn{2}{l}{ Bivariate analysis } & & & Ordinal logistic regression model \\
\hline 0 & 1 & 2 & 3 & P value & OR $(95 \% \mathrm{CI})$ \\
No. $(\%)$ & No. $(\%)$ & No. $(\%)$ & No. $(\%)$ & & \\
\hline
\end{tabular}

COVID-19 infection

\begin{tabular}{|c|c|c|c|c|c|c|}
\hline No & $144(97.30)$ & $30(90.91)$ & $16(80.00)$ & $8(66.67)$ & $0.000^{\mathrm{c}}$ & Reference \\
\hline Yes & $4(2.70)$ & $3(9.09)$ & $4(20.00)$ & $4(33.33)$ & & $3.91 *(1.11,13.86)$ \\
\hline \multicolumn{7}{|l|}{ Family member infected } \\
\hline No & $149(98.03)$ & $26(78.79)$ & $19(90.48)$ & $9(75.00)$ & $0.000^{\mathrm{c}}$ & Reference \\
\hline Yes & $3(1.97)$ & $7(21.21)$ & $2(9.52)$ & $3(25.00)$ & & $3.72 *(1.08,12.77)$ \\
\hline \multicolumn{7}{|l|}{ Essential worker } \\
\hline No & $97(63.82)$ & $20(60.61)$ & $9(42.86)$ & $4(33.33)$ & $0.074^{\mathrm{c}}$ & Reference \\
\hline Yes & $55(36.18)$ & $13(39.39)$ & $12(57.14)$ & $8(66.67)$ & & $2.03 *(1.04,3.97)$ \\
\hline \multicolumn{7}{|l|}{ Gender } \\
\hline Male & $94(61.84)$ & $21(63.64)$ & $10(47.62)$ & $6(50.00)$ & $0.512^{\mathrm{c}}$ & Reference \\
\hline Female & $58(31.16)$ & $12(36.36)$ & $11(52.38)$ & $6(50.00)$ & & $1.09(0.53,2.24)$ \\
\hline \multicolumn{7}{|l|}{ Age } \\
\hline$\leq 30$ & $70(46.05)$ & $18(54.55)$ & $12(57.14)$ & $6(50.00)$ & $0.228^{\mathrm{c}}$ & Reference \\
\hline $31-40$ & $45(29.61)$ & $4(12.12)$ & $7(33.33)$ & $4(33.33)$ & & $0.39 *(0.16,0.92)$ \\
\hline$\geq 41$ & $37(24.34)$ & $11(33.33)$ & $2(9.52)$ & $2(16.67)$ & & $0.53(0.22,1.25)$ \\
\hline \multicolumn{7}{|l|}{ Education } \\
\hline Secondary degree & $39(25.66)$ & $9(28.13)$ & $7(33.33)$ & $3(25.00)$ & $0.781^{\mathrm{c}}$ & Reference \\
\hline Associate degree & $34(22.37)$ & $7(21.88)$ & $7(21.88)$ & $2(16.67)$ & & $1.48(0.61,3.57)$ \\
\hline Bachelor or higher & $79(51.97)$ & $16(50.00)$ & $7(33.33)$ & $7(33.33)$ & & $1.40(0.59,3.28)$ \\
\hline Years spent in the USA, mean (SD) & $10.09(0.28)$ & $9.39(0.49)$ & $10.62(0.54)$ & $11.00(1.04)$ & $0.399^{\mathrm{d}}$ & $1.08(0.97,1.20)$ \\
\hline
\end{tabular}

OR odds ratio, $95 \%$ CI $95 \%$ confidence interval

${ }^{a}$ We applied the model command to measure the proportional odds assumption of ordinal logistic regression models. The $P$ value of this test is equal to 0.150 , indicating the model does not violate the proportional odds assumption

${ }^{\mathrm{b}}$ This is an ordinal variable describing the number of different types of discrimination reported by each survey participant $(0,1,2,3)$

${ }^{\mathrm{c}}$ Fisher's exact test

${ }^{\mathrm{d}}$ ANOVA test

$* P<0.05$

$* * P<0.01$

$* * * P<0.001$ 
Table 4. Predicators of COVID-19 pandemic-related stress among Bhutanese and Burmese refugee participants in the USA in 2020, applying bivariate analysis and adjusted ordinal logistic regression models ${ }^{\mathrm{a}}$

Amount of stress experienced ${ }^{\mathrm{b}}(N=218)$

Bivariate analysis

Ordinal logistic regression model

\begin{tabular}{llllll}
\hline 0 & 1 & 2 & 3 & 4 & $P$ value
\end{tabular} OR (95\% CI)

Amount of discrimination experienced

None

One

Two

Three

COVID-19 infection

No

Yes

Family member infected

No

Yes

Essential worker

No

Yes

Financial crisis

No

Yes

Gender

Male

Female

Age

$\leq 30$

$31-40$

$\geq 41$

Education

Secondary degree

Associate degree

Bachelor or higher
Years spent in the USA, mean (SD)

Bachelor or higher
Years spent in the USA, mean (SD)

\begin{tabular}{|c|c|c|c|c|c|c|}
\hline $62(91.18)$ & $36(65.45)$ & 25 (65.79) & $14(51.85)$ & $15(50.00)$ & $0.000^{\mathrm{c}}$ & Reference \\
\hline $4(5.88)$ & $10(18.18)$ & $7(18.42)$ & $7(25.93)$ & $5(16.67)$ & & $2.70^{* * *}(1.31,5.58)$ \\
\hline $1(1.47)$ & $9(16.36)$ & $4(10.53)$ & $3(11.11)$ & $4(13.33)$ & & $2.48^{* * *}(1.10,5.61)$ \\
\hline $1(1.47)$ & $0(0)$ & $2(5.26)$ & $3(11.11)$ & $6(20.00)$ & & $11.90 * * *(3.52,40.30$ \\
\hline
\end{tabular}

$1(1.47) \quad 0(0) \quad 2(5.26) \quad 3(11.11) \quad 6(20.00)$

$1.90 * * *(3.52,40.30)$

$65(98.48) \quad 50(94.34) \quad 33(86.84) \quad 25(92.59) \quad 25(86.21) \quad 0.067^{\mathrm{c}} \quad$ Reference

$\begin{array}{llllll}1(1.52) & 3(5.66) & 5(13.16) & 2(7.41) & 4(13.79) & 1.14(0.35,3.74)\end{array}$

$\begin{array}{lllllll}67(98.53) & 52(94.55) & 34(89.47) & 24(88.89) & 26(86.67) & 0.075^{\mathrm{c}} & \text { Reference }\end{array}$

$\begin{array}{llllll}1(1.47) & 3(5.45) & 4(10.53) & 3(11.11) & 4(13.33) & 1.30(0.39,4.34)\end{array}$

$\begin{array}{lllllll}41(60.29) & 33(60.00) & 25(65.79) & 18(66.67) & 13(43.33) & 0.363^{\mathrm{c}} & \text { Reference }\end{array}$

$27(39.71) \quad 22(40.00) \quad 13(34.21) \quad 9(33.33) \quad 17(56.67) \quad 1.08(0.63,1.88)$

$\begin{array}{lllllll}50(74.63) & 39(70.91) & 18(48.65) & 15(55.56) & 14(46.67) & 0.013^{\mathrm{c}} & \text { Reference }\end{array}$

$17(25.37) \quad 16(29.09) \quad 19(51.35) \quad 12(44.44) \quad 16(53.33) \quad 2.17^{* *}(1.26,3.73)$

$\begin{array}{lllllll}47(69.12) & 38(69.09) & 20(52.63) & 12(44.44) & 14(47.67) & 0.040^{c} & \text { Reference }\end{array}$

$21(30.88) \quad 17(30.91) \quad 18(47.37) \quad 15(55.45) \quad 16(53.33) \quad 1.97 *(1.06,3.66)$

$31(45.59) \quad 23(41.82) \quad 20(52.63) \quad 17(62.96) \quad 15(50.00) \quad 0.448^{\mathrm{c}} \quad$ Reference

$\begin{array}{llllll}16(23.53) & 20(36.36) & 10(26.32) & 4(14.81) & 10(33.33) & 1.03(0.54,1.98)\end{array}$

$21(30.88) \quad 21(30.88) \quad 8(21.05) \quad 6(22.22) \quad 5(16.67) \quad 0.98(0.48,2.01)$

OR, Odds Ratio; 95\% CI, 95\% Confidence Interval

${ }^{\mathrm{a}}$ We applied the model command to measure the proportional odds assumption of ordinal logistic regression models. The p value of this test is equal to 0.604 , indicating the model does not violate the proportional odds assumption

${ }^{b}$ This is an ordinal variable describing the number of different types of stress reported by each survey participant $(0,1,2,3,4)$

${ }^{\mathrm{c}}$ Fisher's exact test

${ }^{\mathrm{d}}$ ANOVA test

$* P<0.05$

$* * P<0.01$

$* * * P<0.001$

OR $2.48,95 \%$ CI 1.10, 5.61; three types of discriminations: OR $11.90,95 \%$ CI 3.52, 40.30). Experiencing financial crisis (OR 2.17, 95\% CI 1.26, 3.73) and being a female (OR 1.97, 95\% CI 1.06, 3.66) also increased the odds of reporting more types of pandemic-related stress. A similar relationship was observed for participants with associate degree compared with those with secondary degrees (OR $2.34,95 \%$ CI $1.14,4.33)$. 


\section{Discussion}

This study describes characteristics associated with pandemicrelated discrimination and stress in two Asian refugee communities. Notably, the Understanding America Study reported that $0.9,5.9$, and $4.0 \%$ of Asian Americans reported feeling threatened or harassed by others, feeling others be afraid of them, or feeling they were treated with less respect than others as others thought they might have the coronavirus in the prior 7 days based on the data on May 23, 2020 [22]. While our survey did not use the same 7-day time frame, participants reported markedly high rates of discrimination. Our results are consistent with another online survey of Asian Americans during the pandemic [10].

We identity risk factors for experiences with discrimination in these communities, including having had COVID19 , having a family member with COVID-19, and being an essential worker. In addition to experiencing COVID-19related discrimination from others, those and their family members are infected tend to blame themselves or their family members for contracting the diseases, which makes it harder for them to fight COVID-19 related stigma [30]. In other studies, essential and frontline workers have reported high rates of social isolation, stigma, and discrimination due to their heightened risk of COVID-19 and others' fear of infection [31, 32]. In our study, around $40 \%$ of the participants were essential workers. In the USA, a large number of refugees work in the healthcare settings, food supply chain functions, grocery stores, supermarkets, restaurants, and food services establishments, which may expose them to a high risk of pandemic-related discrimination $[16,30]$. However, there has been a lack of education, legislation, and policy to address this discrimination.

Experiencing pandemic-related discrimination is associated with participants' experience of pandemic-related stress. While our cross-sectional study does not establish a causal relationship between pandemic-related discrimination and stress, this finding echoes previous studies showing that discrimination can lead to negative and long-term consequences for mental health [3, 10, 15, 33-35]. While societal strategies for decreasing discrimination are paramount, other researchers have also found that social support and coping strategies can buffer the immediate negative emotional impact of discrimination on Asian Americans [35].

Our study also suggests that experiencing financial crisis during the pandemic increases the likelihood of experiencing higher amounts of pandemic-related stress among Bhutanese and Burmese refugees. Between two predominantly lowincome populations, this is likely to be explained by the impact of financial crisis on individuals' access to basic necessities, such as food, shelter, or healthcare [35-37].

Women were more likely to experience higher amounts of pandemic-related stress than men. This result corresponds with recent findings of high levels of stress and fear of COVID-19 among women [38-40]. This gender difference may be explained by the disproportionate responsibility that many women face in taking care of children and other family members during the pandemic, as well as the disproportionate impact of pandemic-related job losses on women [41].

The study has limitations. Chief among them is reliance on a small, non-representative sample of English-proficient respondents, especially given that English proficiency is reported by just 27 and $28 \%$ of the overall Bhutanese and Burmese populations in the USA, respectively [20]. Additionally, levels of annual household income and educational attainment among our respondents were higher compared with others in their communities. For this reason, results may not be generalizable to the entirety of the Bhutanese and Burmese refugee communities in the USA. We also speculate that people with higher levels of concern about COVID-19 would have been more likely than people with lower levels of concern to complete the survey, so our results may overestimate the prevalence of COVID-19 related stress in these communities. The distribution of COVID-19 cases may also be an underestimate considering the marked shortage of SARS-CoV-2 tests in the USA when data were collected in May 2020 [42]. The prevalence of essential workers may also be underestimated, as it was defined by participants' working status in the week prior to the survey. Those who worked during the pandemic but not during the required timeframe due to none COVID-19 infection-related reasons were coded as non-essential workers. Finally, some of the measures of discrimination and stress have not been validated. We encourage other researchers to replicate our study with a representative sample and novel measures of key variables.

\section{Conclusions}

Reducing pandemic-related discrimination should remain a priority as we work to strengthen our public health response to the pandemic. Public officials should avoid terms such as "China Flu" and consistently condemn racism [1, 43]. Public messaging should remain sciencebased. Because workplace incidents are potential civil rights violations and have been reported by multiple prior studies, we suggest that employers consider proactive and preventive actions $[10,44]$. Programs that enhance social support and teach coping skills may also buffer the immediate psychological impact of discrimination [10, 35]. More importantly, policies, regulations, and education are needed to address pandemic-related stigma and discrimination. Finally, we recommend that larger national studies tracking experiences with discrimination and stress during 
the pandemic include Asian American subgroups with limited English proficiency [26, 45, 46].

Acknowledgments The authors acknowledge Parangkush Subedi, MPH and Curi Kim, MD, MPH from the Department of Health and Human Services, Administration for Children and Families, Office of Refugee Resettlement for their assistance in questionnaire development. None of the individuals acknowledged received compensation for contributions to the study.

Funding The authors did not receive support from any organization for the submitted work. This research did not receive any specific grant from funding agencies in the public, commercial, or not-for-profit sectors.

Availability of Data and Material Available upon request.

Code Availability Available upon request.

\section{Declarations}

Conflicts of Interest The authors declare that they have no conflict of interest.

\section{References}

1. Johns Hopkins Center for Health Security Blame and discrimination attached to COVID-19 - an FAQ for US elected leaders and health officials. 2020

2. Devakumar D, Shannon G, Bhopal SS, Abubakar I. Racism and discrimination in COVID-19 responses. Lancet. 2020;395(10231): 1194.

3. Chen JA, Zhang E, Liu CH. Potential impact of COVID-19-related racial discrimination on the Health of Asian Americans. Am J Public Health. 2020;110(11):1624-7.

4. Wang D, Gee GC, Bahiru E, Yang EH, Hsu JJ. Asian-Americans and Pacific Islanders in COVID-19: emerging disparities amid discrimination. J Gen Intern Med. 2020:1-4.

5. Dhanani LY, Franz B. Unexpected public health consequences of the COVID-19 pandemic: a national survey examining anti-Asian attitudes in the USA. Int J Public Health. 2020;65(6):747-54.

6. Margolin J. FBI warns of potential surge in hate crimes against Asian Americans amid coronavirus. ABC News 272020.

7. Jackson C, New Center for Public Integrity/Ipsos Poll Finds Most Americans Say the Coronavirus Pandemic is a Natural DisasterIpsos 2020.

8. Turton N. Asian Pacific Policy and Planning Council. Anti-Asian incidents across U.S. near 1,900 over 8-week period. 2020.

9. Misra S, Le PD, Goldmann E, Yang LH. Psychological impact of anti-Asian stigma due to the COVID-19 pandemic: a call for research, practice, and policy responses. Psychol Trauma Theory Res Pract Policy. 2020.

10. Lee S, Waters SF. Asians and Asian Americans' experiences of racial discrimination during the COVID-19 pandemic: impacts on health outcomes and the buffering role of social support. Stigma Health. 2020.

11. Carter RT. Racism and psychological and emotional injury: recognizing and assessing race-based traumatic stress. Couns Psychol. 2007;35(1):13-105.
12. Kluge HHP, Jakab Z, Bartovic J, D'Anna V, Severoni S. Refugee and migrant health in the COVID-19 response. Lancet. 2020;395(10232):1237-9.

13. Do M, McCleary J, Nguyen D, Winfrey K. Mental illness public stigma and generational differences among Vietnamese Americans. Community Ment Health J. 2020:1-15.

14. Wynaden D, Chapman R, Orb A, McGowan S, Zeeman Z, Yeak S. Factors that influence Asian communities' access to mental health care. Int J Ment Health Nurs. 2005;14(2):88-95.

15. Shannon PJ, Wieling E, Simmelink-McCleary J, Becher E. Beyond stigma: barriers to discussing mental health in refugee populations. J Loss Trauma. 2015;20(3):281-96.

16. New American Economy. Refugee workers on the frontlines and as essential workers. 2020. https://research.newamericaneconomy. org/report/refugee-on-thefrontlines-covid-19/

17. New American Economy. Covid-19: immigrant workers are essential in securing U.S. food supply chain. 2020. https://research. newamericaneconomy.org/report/covid-19-immigrant-foodworkers/

18. Taylor S, Landry CA, Rachor GS, Paluszek MM, Asmundson GJ. Fear and avoidance of healthcare workers: an important, underrecognized form of stigmatization during the COVID-19 pandemic. J Anxiety Disord. 2020:102289.

19. McKay D, Heisler M, Mishori R, Catton H, Kloiber O. Attacks against health-care personnel must stop, especially as the world fights COVID-19. Lancet. 2020;395(10239):1743-5.

20. López G, Ruiz NG, Patten E. Key facts about Asian Americans, a diverse and growing population. Pew Res Center. 2017;8. https:// www.pewresearch.org/fact-tank/2017/09/08/key-facts-aboutasian-americans/

21. Trieu MM, Vang CY. A portrait of refugees from Burma/Myanmar and Bhutan in the United States. J Asian Am Stud. 2015;18(3):34769. https://doi.org/10.1353/jaas.2015.0029.

22. Understanding America Study. Understanding coronavirus in America. 2020. https://covid19pulse.usc.edu/?methods. Accessed $09 / 10 / 2020$

23. Liu N, Zhang F, Wei C, Jia Y, Shang Z, Sun L, et al. Prevalence and predictors of PTSS during COVID-19 outbreak in China hardest-hit areas: gender differences matter. Psychiatry Res. 2020:112921.

24. Islam SD-U, Bodrud-Doza M, Khan RM, Haque MA, Mamun MA. Exploring COVID-19 stress and its factors in Bangladesh: a perception-based study. Heliyon. 2020;6(7):e04399.

25. Juang LP, Cookston JT. Acculturation, discrimination, and depressive symptoms among Chinese American adolescents: a longitudinal study. J Prim Prev. 2009;30(3-4):475-96.

26. Spoorthy MS, Pratapa SK, Mahant S. Mental health problems faced by healthcare workers due to the COVID-19 pandemic - a review. Asian J Psychiatr. 2020;51:102119.

27. Massachusetts Government. COVID-19: essential services. 2020. https://www.mass.gov/info-details/covid-19-essential-services. Accessed 06/16/2020.

28. Liebkind K, Jasinskaja-Lahti I. The influence of experiences of discrimination on psychological stress: a comparison of seven immigrant groups. J Community Appl Soc Psychol. 2000;10(1):1-16.

29. Ong AD, Fuller-Rowell T, Burrow AL. Racial discrimination and the stress process. J Pers Soc Psychol. 2009;96(6):1259-71.

30. Ransing R, Ramalho R, de Filippis R, Ojeahere MI, Karaliuniene R, Orsolini L, et al. Infectious disease outbreak related stigma and discrimination during the covid-19 pandemic: drivers, facilitators, manifestations, and outcomes across the world. Brain Behav Immun. 2020

31. Sharma V, Scott J, Kelly J, VanRooyen MJ. Prioritizing vulnerable populations and women on the frontlines: COVID-19 in humanitarian contexts. Int J Equity Health. 2020;19(1):1-3. 
32. Singh R, Subedi M. COVID-19 and stigma: social discrimination towards frontline healthcare providers and COVID-19 recovered patients in Nepal. Asian J Psychiatr. 2020;53:102222.

33. Corrigan PW, Watson AC. Understanding the impact of stigma on people with mental illness. World Psychiatry. 2002;1(1):16-20.

34. Thompson VLS, Noel JG, Campbell J. Stigmatization, discrimination, and mental health: the impact of multiple identity status. Am J Orthopsychiatry. 2004;74(4):529-44.

35. Litam SDA, Oh S. Ethnic identity and coping strategies as moderators of COVID-19 racial discrimination experiences among Chinese Americans. Couns Outcome Res Eval. 2020:1-15.

36. Shigemura J, Ursano RJ, Morganstein JC, Kurosawa M, Benedek DM. Public responses to the novel 2019 coronavirus (2019-nCoV) in Japan: mental health consequences and target populations. Psychiatry Clin Neurosci. 2020;74(4):281-2.

37. Kentikelenis A, Karanikolos M, Papanicolas I, Basu S, McKee M, Stuckler D. Health effects of financial crisis: omens of a Greek tragedy. Lancet. 2011;378(9801):1457-8.

38. Qiu J, Shen B, Zhao M, Wang Z, Xie B, Xu Y. A nationwide survey of psychological distress among Chinese people in the COVID-19 epidemic: implications and policy recommendations. Gen Psychiatr. 2020;33(2).

39. Sakib N, Bhuiyan AI, Hossain S, Al Mamun F, Hosen I, Abdullah AH, et al. Psychometric validation of the Bangla Fear of COVID-19 Scale: confirmatory factor analysis and Rasch analysis. Int J Ment Heal Addict. 2020:1-12

40. Bitan DT, Grossman-Giron A, Bloch Y, Mayer Y, Shiffman N, Mendlovic S. Fear of COVID-19 scale: psychometric characteristics, reliability and validity in the Israeli population. Psychiatry Res. 2020:113100.

41. McLaren HJ, Wong KR, Nguyen KN, Mahamadachchi KND. Covid-19 and women's triple burden: vignettes from Sri Lanka, Malaysia, Vietnam and Australia. Soc Sci. 2020;9(5):87.

42. Bai Y, Yao L, Wei T, Tian F, Jin D-Y, Chen L, et al. Presumed asymptomatic carrier transmission of COVID-19. JAMA. 2020;323(14):1406-7.

43. Gee GC, Ro MJ, Rimoin AW. Seven reasons to care about racism and COVID-19 and seven things to do to stop it. Am J Public Health. 2020:954-955.

44. Occupation Health and Safety. Coronavirus: workplace safety and discrimination concerns. 2020. https://ohsonline.com/articles/2020/ 03/17/coronavirus-workplace-safety-and-discrimination-concerns. aspx

45. Gurung A, Subedi P, Zhang M, Li C, Kelly T, Kim C, et al. Culturally-appropriate orientation increases the effectiveness of mental health first aid training for Bhutanese refugees: results from a multi-state program evaluation. J Immigr Minor Health. 2020:1-8.

46. Subedi P, Li C, Gurung A, Bizune D, Dogbey MC, Johnson CC, et al. Mental health first aid training for the Bhutanese refugee community in the United States. Int J Ment Heal Syst. 2015;9(1):20.

47. Marmot MG, Bell R. How will the financial crisis affect health? BMJ. 2009;338:b1314.

Publisher's Note Springer Nature remains neutral with regard to jurisdictional claims in published maps and institutional affiliations. 